\title{
Marked themes in English and Norwegian academic texts in the field of didactics ${ }^{1}$
}

\author{
Sylvi Rørvik, Marte Monsen \\ Inland Norway University of Applied Sciences (Norway)
}

\begin{abstract}
This study investigates the use of marked themes in the field of didactics. The material comprises research articles written in L1 English and Norwegian, and L2 English. The aim is to shed light on contrastive differences between Norwegian and English that may be used to inform novice writers about central textual features of academic texts within the field of didactics, and about potential transfer-related features that might give their texts a "foreign accent". The results show that there are contrastive differences in the realization of and meanings expressed by marked themes, but that these differences cause few problems for L2 writers. The study further supports findings from previous research that show the importance of text type and academic discipline for thematic structure.
\end{abstract}

Keywords: thematic structure, marked themes, contrastive analysis, English/Norwegian

\section{Introduction}

Text structure is a recurring topic in the literature, and studies have suggested that the structure of a text may be influenced by text type (Davies, 1997, Hasselgård, 2014), the discipline within which the text is written (Hyland, 2000, North, 2005b, Ebrahimi et al., 2014, Ebrahimi, 2016, Babaaii et al., 2016), the language in which it is written (Hasselgård, 2005) and the language background of the writer (Hasselgård, 1998, Rørvik, 2013). It has also been shown that different languages may have different means of realization for the same text-structuring function (Moyano, 2016). On the basis of contrastive studies, conflicting evidence has emerged regarding the existence of differences in this area in different text types: for instance, in a comparisons of fiction texts in English and Norwegian it has been shown that Norwegian permits a higher frequency of non-subjects in initial position than does English (Hasselgård, 1998, 2004, 2005). On the other hand, a study of argumentative newspaper texts found no contrastive difference as regards the frequency of marked themes (Rørvik, 2013: 51-52). Given this variability, contrastive corpus-based studies of academic writing in a range of disciplines and including all text types within the

\footnotetext{
${ }^{1}$ We would like to express our gratitude towards Bård Uri Jensen for his invaluable help with the statistical groundwork for this study. We also acknowledge the useful comments from two anonymous reviewers.
}

Corpora et comparatio linguarum: Textual and contextual Perspectives. Edited by Signe Oksefjell Ebeling and Hilde Hasselgård. BeLLS Vol 9, No 1 (2018), DOI 10.15845/bells.v9i1.1521. Copyright @ $\odot$ by the author. Open Access publication under the terms of CC-BY-NC-4.0. 
disciplines are essential as a starting point for research-based teaching of academic writing (cf. Carter-Thomas \& Rowley-Jolivet, 2008), not least because such studies may contribute to the definition of individual disciplines: if the writing within one putative field is found to differ from the writing in other fields with respect to the variable(s) under investigation, one may argue that the examined field has a set of writing conventions to which authors must adhere and of which novice writers should be made aware (Gosden, 1992: 207, 221). It is of course possible for a discipline to encompass many different text types, and it is therefore desirable to broaden the knowledge base regarding writing conventions within a field or discipline through a range of studies examining the ongoing development of text types published within the field (cf. e.g. Gray, 2015). For pedagogical purposes it is also important to investigate whether transfer from the writers' L1 can influence their production in the L2, and it is therefore necessary to carry out contrastive studies of material that includes nativespeaker texts in the learners' L1 as well as in the L2. It is of course an added bonus if one can also include L2 texts, i.e. non-native target-language texts, as this enables the study of transfer-related difficulties in practice and not just as a potentiality based on differences between native-speaker L1 and native-speaker L2 (cf. Lado, 1957: 70). The aim of such a comparison would thus be to move from the "strong" hypothesis of contrastive analysis to a weaker version that can then be complemented by a contrastive interlanguage analysis at a later stage (cf. the discussion in Gilquin, 2000/2001, 2008 and Granger, 1996).

The present study is a first attempt at providing insights about contrastive differences between Norwegian and English that may be used to inform novice writers about central textual features of academic texts within the field of didactics, and about potential transferrelated features that might give their texts a "foreign accent" (Shaw, 2004: 81). To this end, a contrastive study has been carried out of published academic texts written in L1 Norwegian and L1 and L2 English. The design of the study is thus similar to that employed by Shaw (ibid.), but the discipline is different, as well as the languages involved and language backgrounds of the writers: Shaw investigated articles within the field of economics written by Danes in Danish and English and in English by native speakers, or at least articles written by authors with Anglo-Saxon names (ibid.: 77; see further Section 2 below). More specifically, the focus of the present study is on the frequency and realization of marked themes (roughly defined as non-subjects in initial position, see further Halliday, 2004: 64105), as well as the meanings expressed by these. The following research questions are addressed:

1. What are the similarities and differences between L1 Norwegian and L1 English writers in the field of didactics as regards the following features:

- $\quad$ the frequency of marked themes

- the functions of marked themes

- $\quad$ the realizations of marked themes

- $\quad$ the meanings expressed by marked themes

2. To what extent have Norwegian writers of L2 English in the field of didactics managed to adapt to English conventions regarding the use of marked themes? Is there any evidence of transfer from Norwegian in their use of marked themes?

The remainder of this article is structured as follows: Section 2 presents an overview of relevant previous research, while Section 3 defines the central theoretical concepts and 
analytical framework employed in the present study. The material and method are introduced in Section 4, and Section 5 contains the discussion of the results. Finally, Section 6 comprises a brief summary and conclusion.

\section{Previous research on thematic structure}

Previous studies typically focus on text structure or thematic structure in general, and not marked themes in particular, so this is necessarily reflected in our presentation of previous research, which focuses on studies discussing factors influencing thematic structure, such as text type, field/academic discipline, language, and the language background of the writers. It should also be noted that not all studies define theme in the same way as the present study does, nor is the unit of analysis always the same (or even always clearly stated). In some cases we have therefore "translated" the terminology used in previous studies to make it fit the terminology applied in the present study. For instance, Shaw (2004) investigates sentence-initial elements, and uses the orthographic sentence as his unit of analysis, not the T-unit.

Davies (1997) suggests that theme analysis may help distinguish between different texttypes and genres. She investigates 14 texts within genres like "textbooks", "academic papers" and "the modern novel", and illustrates that different text types make use of different themes, but without formulating any clear-cut distinctions between different text types. Further support for the claim that text type influences thematic structure can be found in a study of initial adjuncts in news and fiction (Hasselgård, 2014), where it is shown that these two genres differ both as regards the frequency of initial adjuncts, which are more common in fiction than in news, and in the meanings expressed by them, with the most prominent difference being that initial adjuncts expressing 'time' are more frequent in fiction than in news.

Several previous studies have also shown that the discipline within which the texts are written may influence text structure. North (2005a) actually questions the extent to which communication skills can be transferred across disciplines, and in a study of L1 English student texts she found that students from the fields of arts and sciences differed in their use of theme according to their subject background (North 2005b). Differences in the frequency/proportion of marked themes have also been found to exist between published research articles from various disciplines. For instance, Heng and Ebrahimi (2012) found that abstracts in research articles in applied linguistics had a lower proportion of marked themes than research articles in economics. Similarly, Babaii et al. (2016) investigated the frequency of marked themes in research articles in mechanical engineering, biomedical engineering, horticulture, and environmental sciences, concluding that marked themes are more frequent in mechanical engineering than in the three other disciplines. One final example comes from a study of research-article introductions (Valipour et al., 2017), where the results indicate that chemistry exhibits a higher proportion of marked themes than does linguistics and software engineering.

There are also previous studies that investigate the influence of academic discipline on the meanings expressed by marked themes, for instance the above-mentioned Heng and Ebrahimi (2012), and Ebrahimi (2016). Heng and Ebrahimi (2012) show that linguistics and economics are fairly similar regarding the proportions of marked themes expressing 'time', 'cause', 'means', and 'condition', but that marked themes express 'contrast' more frequently in economics than in linguistics. Ebrahimi (2016) finds that chemistry has more themes expressing 'time' than does psychology and applied linguistics, and that 'condition' is more frequently expressed by marked themes in applied linguistics than in psychology and 
chemistry. A further finding is that 'location' is a frequent meaning in both applied linguistics and psychology, but less frequent in chemistry.

A further set of studies investigate the frequency of marked themes and meanings expressed by marked themes either in one discipline or in several, but without distinguishing between them. We mention these briefly here because they involve disciplines different from the one investigated in this study, and the findings may therefore be compared to ours in an attempt to pinpoint whether and, if so, how, the writing conventions in didactics differ from those of other disciplines. First, Gosden (1992) found that the proportion of marked themes in a corpus consisting of research articles from physics, chemistry, and biological sciences was approximately $32 \%$. It should be noted, however, that Gosden's definition of marked themes appears to include some structures that are are excluded from the framework applied in the present study (principally this concerns adverbial conjuncts). Furthermore, Gosden found that the most frequent meanings expressed by marked themes were 'place', 'contrastive'/'concessive' meanings, 'time', and 'cause'. A second study worth mentioning investigates theme in the method and discussion sections of biology journal articles (Martínez, 2003). In this material approximately $17 \%$ of the themes are marked, and nearly all of these are circumstance adverbials. The most frequent meanings expressed are 'purpose', 'time', and 'place'. The results presented by Gosden (1992) and Martínez (2003) thus support the idea that academic discipline influences the proportion of and meanings expressed by marked themes.

We now turn to relevant previous contrastive studies. Of particular relevance for the present study are studies of fiction material from the English-Norwegian Parallel Corpus that indicate a greater tolerance for non-subjects in initial position in Norwegian than in English (Hasselgård, 1998, 2004, 2005). On the basis of these studies, it would seem that there are clear cross-linguistic differences between Norwegian and English, in that Norwegian writers use more marked themes than do English writers. However, an investigation of texture in English and Norwegian argumentative texts found no such contrastive difference, suggesting that text-type differences play a part contrastively as well (Rørvik, 2013). Similarly, Shaw (2004) found more initial circumstance adverbials (i.e. one type of marked theme) in Danish economics articles than in English economics articles. Interestingly, Shaw also included articles written in English by Danish writers, and found that this L2 English material "is more like Danish than like English written by [native speakers]" (ibid.: 79) as regards features that correspond to the marked themes investigated in the present study. Danish and Norwegian are very closely related languages, so Shaw's results form a very important basis for comparison with the results of the present study. The final contrastive study to be included in this overview has already been briefly introduced above, where its results were mentioned as evidence for text-type/genre differences: Hasselgård (2014) not only examined differences between news and fiction, but also between English and Norwegian texts belonging to these two genres/text types. She found slightly higher proportions of initial adjuncts in Norwegian than in English, and also some differences in the types of meanings expressed by these adjuncts: in the fiction material, 'time' was more frequently expressed in Norwegian than in English. This difference also occurred in news, but was less pronounced there. In addition, the meaning of 'manner' was much more frequent in Norwegian news than in English news. Hasselgård also looked at the realization of adverbials, and found that there seem to be more initial adverbials realized by single adverbs in Norwegian (both genres) than in English. The same is true for prepositional phrases.

As we have seen, previous studies have indicated that thematic conventions may vary from text type to text type, and there may also be different expectations in different academic disciplines. This comes in addition to the potential cross-linguistic differences between Norwegian and English. Hence, in order for teachers to be able to teach academic writing 
within the field of didactics, an investigation into the specific conventions of this field is necessary. Additionally, by adding L2 English material, we can examine whether Norwegian academics adapt their writing style when writing in a foreign language.

\section{Terms and definitions}

This section presents the analytical framework and definitions employed in the present study.

\subsection{Theme and the unit of analysis}

The present study employs a definition of theme that is largely in line with that of Halliday (2004: 79), according to which theme comes first in the clause and "ends with the first constituent that is either participant, circumstance or process". A strict application of this definition would entail the clause as the unit of analysis, but, in line with previous studies in the field (cf. e.g. Hasselgård, 1998, 2004, 2005 and Rørvik, 2013), we have chosen to use Tunits instead of clauses as the basis for our analysis. T-units are defined as a main clause together with any associated dependent clauses (Hunt, 1965). This has two implications for the thematic analysis, both of which are illustrated in example (1):

(1) a. She knew that videos were being taken of Lila at the setting

b. but unless a teacher took the time to show them to her she did not see them. (L1Eng) $)^{2}$

First, the choice of T-units as the unit of analysis means that any sentence with more than one main clause will be split into several T-units, each with its own theme. Thus, the sentence in example (1) consists of two T-units ( $a$ and $b$ ), since there are two main clauses, and each of these has a theme (in italics). Secondly, a T-unit can have a dependent clause as theme, which is illustrated in the second T-unit in example (1). A strict Hallidayan approach here would mean that we analyzed the themes in the dependent clause and the main clause separately, but such a micro-level approach would mean that we would lose track of the development of the text.

Next we will introduce the distinction between unmarked and marked themes, using declarative sentences as examples (for details regarding thematic structure in other sentence types, see Halliday, 2004: 75-79). In declarative sentences, the unmarked choice of theme is to conflate it with the grammatical subject, as illustrated in example (2):

(2) Samisk er et offisielt språk i Norge, [...] (L1Nor)

"Sami is an official language in Norway, [...]"

In example (2) the first constituent is the grammatical subject Samisk, which constitutes an unmarked theme. By contrast, example (3) has the circumstance/adverbial In the United States (U.S.) in initial position:

\footnotetext{
${ }^{2}$ Each example has been provided with a tag identifying the corpus from which it has been extracted.
} 
(3) In the United States (U.S.), assessment has received a great deal of attention from both the popular press (Ravitch, 2011) and education scholars (Darling-Hammond, 2014). (L1Eng)

Since the first element in example (3) is not the subject, the theme in this T-unit is considered to be marked.

\subsection{Functions of marked themes}

There is only a limited set of options as regards the functions of marked themes. In cases where the marked theme is a circumstance/adverbial, the function will be 'Adjunct', as exemplified in (4):

(4) Dersom jeg kun hadde sittet og observert $i$ klasserommet, hadde det ikke vært mulig å få så detaljerte analyser. (L1Nor)

"If I had only conducted classroom observation, it would not have been possible to get such detailed analyses."

Whenever the marked theme is realized by a non-adverbial (i.e. an object or predicative of some kind), the function is 'Complement'. In example (5), for instance, the author has fronted the subject predicative:

(5) Perhaps more important to the participants in this study than rank or location, was that engagement in $\mathrm{CoP}$ resulted in the creation of trusting relationships which served to break their feeling of academic isolation. (L1Eng)

The third potential function of marked themes is 'Predicator', used for any fronted process (i.e. verbal). However, this did not occur in our material, so it will not be discussed further here.

\subsection{Realizations of marked themes}

Numerous structures functioning as marked themes were found in the material, but most with very low frequencies. We have therefore chosen to limit the present overview to the three most frequently occurring constructions: dependent clauses, prepositional phrases, and adverb phrases (includes single adverbs). These categories do not require a lot of explanation, but for the sake of completeness we illustrate each of them here. First, example (6) illustrates a theme realized by a dependent clause:

(6) Når det gjelder metoder finner en så godt som alle tilnærminger innen samfunnsforskning. (L1Nor)

"When it comes to methods you can find practically every approach within social sciences."

In example (7) the theme is realized by a prepositional phrase: 
(7) At the pedagogical end of the continuum, we hold that teachers conceive of assessment as serving the purpose of informing instruction and improving student learning. (L1Eng)

Finally, the theme in example (8) is realized by an adverb phrase:

(8) More recently, Brown, Chaudhry, and Dhamija (2015) investigated 1,645 Northern Indian secondary (primarily private) school teachers' conceptions of assessment. (L1Eng)

Having defined the concepts related to the form, function, and realizations, we now turn to the meanings expressed by the marked themes.

\subsection{Meanings of marked themes}

As was the case with the realizations of marked themes, a range of different meanings were expressed in the corpora. In this paper we will include those that were among the top three in each subcorpus, resulting in the following list of meanings (all adverbial in nature): 'time', 'place', 'condition', 'instrument', 'concession', 'reason', and 'purpose'.

The meaning of 'time' is illustrated in example (9), where the prepositional phrase in italics functions as theme:

(9) I løpet av disse samtalesekvensene som totalt dekker 5 minutter, stiller læreren 29 spørsmål. (L1Nor)

"During these speech sequences which cover in total 5 minutes, the teacher asks 29 questions."

Marked themes expressing 'place' may have a non-literal meaning, or be geographical, as is illustrated by example (10):

(10) In New Zealand narrative formative assessments are used widely to support children's learning in ECE settings (Carr, 2009) [...] (L1Eng)

'Condition' is frequently expressed by means of dependent clauses starting with if, as illustrated by example (11):

(11) If one believes that assessments are used to hold teachers and schools accountable, then teachers can use this perspective to frame or limit their focus when they need to make decisions about assessments in their classrooms. (L1Eng)

The 'instrument' meaning entails a theme that describes the procedures used to achieve the objectives of the investigation. Example (12) is a typical example, where the marked theme describes the method employed in the study:

(12) Using exploratory principal axis factoring and cluster analysis, we examined teachers' conceptions of assessment based on their responses to the COA instrument. (L1Eng) 
Marked themes expressing 'concession' are exemplified by the dependent clause in (13):

(13) Selv om de svarer anonymt, kan svarene deres reflektere hva de tror er forventete eller ønskelige holdninger i en gitt situasjon, mer enn det de virkelig føler og mener om sakene som skjemaet dreier seg om. (L1Nor)

"Even though they respond anonymously, their answers may reflect what they think of as expected or desired attitudes in a given situation, more than what they really feel and think about the issues that the form asks about."

The two final meanings included here are 'reason' and 'purpose'. These may be somewhat similar in meaning, in the sense that 'purpose' meanings can be paraphrased as, for instance, "because $\mathrm{X}$ is so, we need to do $\mathrm{Y}$ to avoid it", but in practice the coding proved relatively unproblematic, as the occurrences were nearly all prototypical. The following two examples are representative of the vast majority of cases:

(14) Because our factors were moderately correlated, using an oblique rotation should "theoretically render a more accurate, and perhaps a more reproducible solution" (Costello \& Osborne, 2005, p. 3). (L1Eng)

Example (14) is a clear case of a marked theme expressing 'reason', as signaled by because.

(15) For å oppnå tilfredsstillende reliabilitet for denne faktoren måtte én av påstandene i settet tas ut. (L1Nor)

"To achieve satisfactory reliability for this factor, one of the statements in the set had to be removed."

Equally, example (15) is an uncontroversial instance of 'purpose', where the dependent clause would require substantial changes to give it a 'reason' meaning instead.

3.5 The cross-linguistic applicability of terms and definitions

English and Norwegian are very similar languages, and the functions, realizations and meanings expressed by marked themes discussed in Sections 3.2 through 3.4 are among the inventory of possibilities in both languages, with the exception of non-finite -ing clauses, which do not occur in Norwegian. The same thing technically applies to the definition of marked themes as non-subjects in initial position, but there is a potential complication that might increase the proportion of marked themes in Norwegian: Norwegian is a V2-language (Faarlund et al., 1997: 859), so when a sentence starts with a non-subject element that does not exhaust the thematic potential (e.g. an adverbial conjunct), the finite verb is placed before the subject. This could potentially result in a higher frequency of marked themes, since initial processes would be counted as such. However, as mentioned in Section 3.2, this did not occur in our material, so it will not be discussed as a potential factor influencing the quantitative results presented in Section 5.1. 


\section{Material and method}

The study was designed to enable a contrastive analysis of L1 material in Norwegian and English, with an extra dimension being provided by L2 material in English written by native speakers of Norwegian, which afforded the opportunity to investigate whether L1 Norwegian writers transfer Norwegian patterns of marked-theme usage into their construction of English texts. Thus, the material comprises three subcorpora: 'L1Eng' and 'L1Nor', which contain published academic articles written by native speakers of English and Norwegian, respectively, and 'L2Eng', which contains published academic articles written in English by native speakers of Norwegian. ${ }^{3}$ There are 11 complete texts in each subcorpus, collected from the following journals: L1Eng: Teaching and Teacher Education; L1Nor: NOA Norsk som andrespråk, Studies in Education, Norsk Pedagogisk Tidsskrift, Nordisk Pedagogik, Heimen, and Nordic Studies in Education; L2Eng: Acta Didactica Norge and Nordic Journal of Modern Language Methodology.

Table 1 provides an overview of the material as regards the number of words and number of T-units in each subcorpus.

Table 1. Overview of the material.

\begin{tabular}{|c|c|c|}
\hline \multirow{2}{*}{ Subcorpora } & Number of words & Number of T-units \\
\hline L1Eng & 90,052 & 3,414 \\
\hline L1Nor & 56,161 & 2,732 \\
\hline L2Eng & 75,529 & 3,130 \\
\hline Total & 221,742 & 9,276 \\
\hline
\end{tabular}

In total, the material comprises some 221,000 words and nearly 9,300 T-units, but as is obvious from Table 1 the English corpora contain longer texts than the Norwegian corpus, both in terms of number of words and number of T-units.

The texts were segmented and coded manually, since there is no automatic procedure for the identification of themes. The categories employed were introduced in Section 3 above.

After the manual segmentation and coding, statistical calculations were carried out. The material is relatively small in size, but the findings from the present investigation could nonetheless be used as the basis for hypothesis-forming with future studies in mind. It is therefore important to ensure that any differences identified are not due to chance. The statistical calculations have been carried out using RStudio (RStudio Team, 2015), in accordance with the following general procedure:

1. The frequency for the occurrence of each variable per T-unit or marked theme was calculated for each text (e.g. the number of marked themes divided by the number of Tunits). ${ }^{4}$

\footnotetext{
${ }^{3}$ It should be noted that the authors have been assigned native-speaker status primarily on the basis of their names, following the practice outlined by Shaw (2004: 72). However, with regard to the writers with a Norwegian background it is possible to say for certain that they are native speakers of Norwegian, since the relatively-speaking smaller context makes it possible to know more about the people behind the names.

${ }^{4}$ In section 5, frequencies per $100 \mathrm{~T}$-units or 100 marked themes serve as the starting point for the discussion. This represents an upscaled version of the numbers employed in the statistical calculations, but has the obvious advantage of reducing the number of decimal points and therefore represents an improvement from the point of view of readability.
} 
2. Tests were carried out to check whether the frequencies for each variable had normal distribution in each of the subcorpora. These tests included both the Shapiro-Wilks test and the function gvlma from the R package 'gvlma' (Peña and Slate, 2014), since the Shapiro-Wilks test is less than ideal for small samples (cf. Jensen, 2017: 84). In addition to these tests the density plots for each variable were inspected visually.

3a. In cases where all indicators listed under step 2 suggested that the distribution was normal and thus satisfied the requirements for a parametric test, step 3 was to carry out a one-way ANOVA with a Tukey post-hoc test.

3b. In cases where the distribution was not normal, a logit transformation was carried out following the procedure and $\mathrm{R}$ code outlined by Jensen (ibid.). After the transformation the data were once again tested using the gvlma function in $\mathrm{R}$, and, upon confirmation that the distribution was normal following the logit transformation, a one-way ANOVA with a Tukey post-hoc test was carried out.

4. In those cases where the ANOVA and Tukey post-hoc test indicated a significant difference $(\mathrm{p}<0.05)$ between two subcorpora, the effect size and $95 \%$ confidence interval were calculated using the function cohen.d from the $\mathrm{R}$ package 'effsize' (Torchiano, 2017). Following Sawilowsky (2009: 599), these rules of thumb for interpreting effect sizes (the d-value) were applied: 'very small' for $\mathrm{d}=0.01$, 'small' for $\mathrm{d}=0.2$, 'medium' for $\mathrm{d}=0.5$, 'large' for $\mathrm{d}=0.8$, 'very large' for $\mathrm{d}=1.2$, and 'huge' for $\mathrm{d}=2.0$.

\section{Results}

The presentation of the results will be structured as follows: first, the proportions of marked themes in the three corpora will be discussed. Next come the functions and realizations of marked themes, followed by the meanings expressed by the marked themes. We will present the results in table form, with a visual representation of the corpus-internal distribution added for those variables where one or more significant differences were identified.

\subsection{The proportion of marked themes}

Table 2 shows the frequencies of marked themes per $100 \mathrm{~T}$-units in each text of the three corpora. The final row shows the average frequency for each subcorpus.

Table 2. The frequency of marked themes per $100 \mathrm{~T}$-units in each text and the average frequency per corpus.

\begin{tabular}{|c|c|c|c|}
\hline & L1Eng & L1Nor & L2Eng \\
\hline Text 1 & 20.8 & 19.6 & 19.3 \\
\hline Text 2 & 25.4 & 30.6 & 25.7 \\
\hline Text 3 & 17.6 & 19.4 & 18.3 \\
\hline Text 4 & 19.8 & 31.4 & 15.8 \\
\hline Text 5 & 28.5 & 18.1 & 16.6 \\
\hline Text 6 & 34.8 & 27.3 & 15.4 \\
\hline Text 7 & 28.0 & 17.3 & 21.9 \\
\hline Text 8 & 35.0 & 28.8 & 17.1 \\
\hline Text 10 & 31.0 & 26.9 & 19.9 \\
\hline Text 11 & 25.8 & 17.3 & 21.9 \\
\hline Average frequency & 29.8 & 22.3 & 18.3 \\
\hline
\end{tabular}


The contents of Table 1 seem to suggest that there is a slight cross-linguistic difference, with marked themes being more frequent in L1 English than in L1 Norwegian. The frequency of marked themes is even lower in L2 English than in Norwegian, suggesting that if transfer plays a role here, it cannot be the only factor affecting the L2 writers. However, the statistical calculations show that the only significant difference is between the L1 English texts and the L2 English texts ( $\mathrm{p}=0.0015121)$, with a very large effect size (Cohen's $\mathrm{d} \approx 1.7, \mathrm{CI}(95 \%) \approx$ $[0.6,2.8]$. The difference between L1Eng and L2Eng is easier to grasp when presented visually, as in Figure 1.

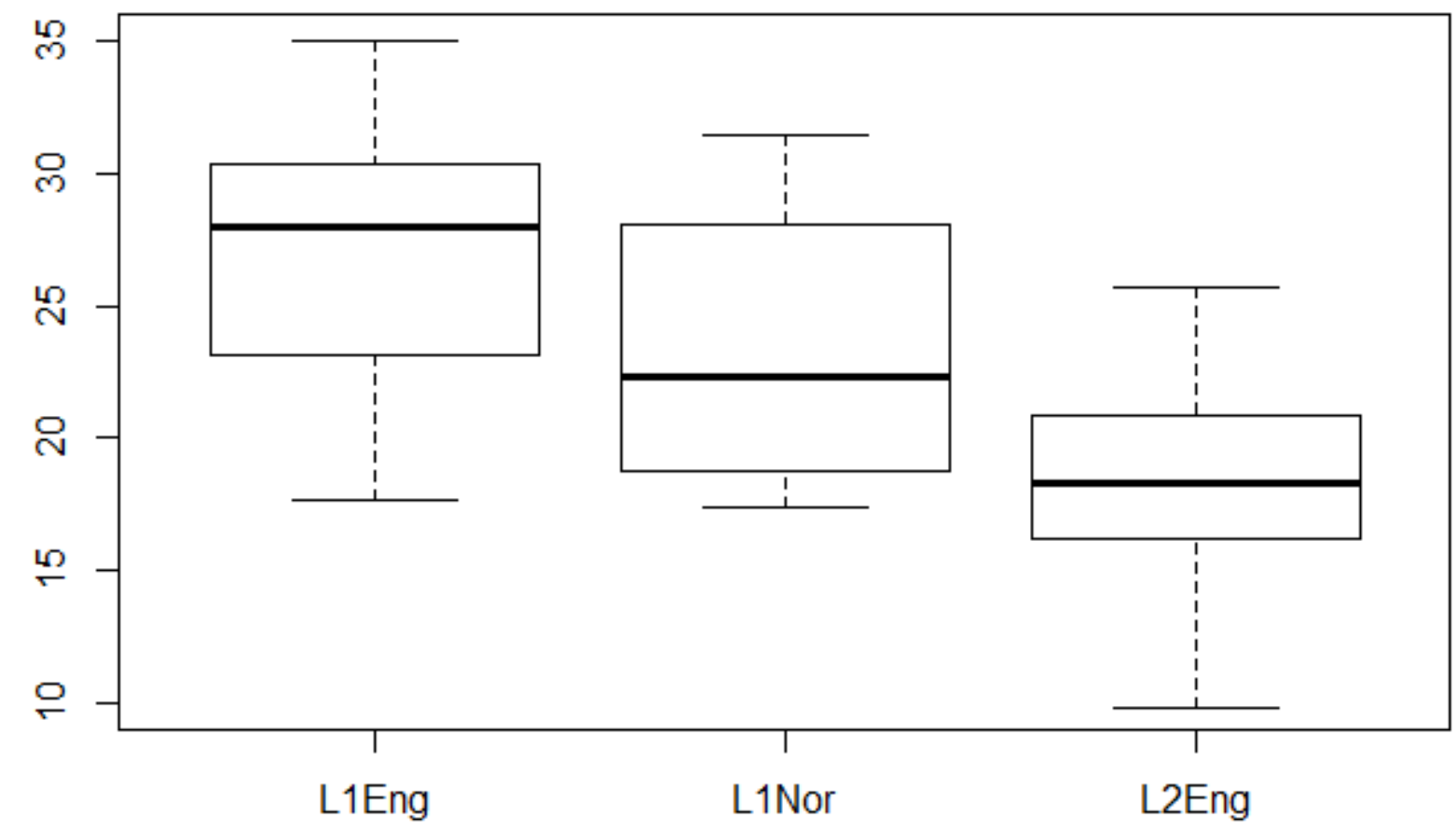

Figure 1. Distribution of marked themes per $100 \mathrm{~T}$-units in each subcorpus.

The boxplots in Figure 1 clearly show that the writers in the L1Eng corpus use more marked themes overall than the L2 writers of English do. There is a certain amount of overlap between the plots, due to the corpus-internal variation in each group of writers, but it is nonetheless clear that the majority of L1 writers use more marked themes than the majority of L2 writers. Given the lack of a significant contrastive difference between the L1 texts in English and Norwegian as regards the frequency of marked themes, we must conclude that this is one area where the L2 writers of English have not successfully adapted to English discourse conventions, but probably not due to (direct) transfer from Norwegian.

Many of the previous studies discussed in Section 3 report their findings in percentages, e.g. the percentage of marked themes out of all the themes in a corpus. It is therefore difficult to compare the results from previous studies with the normalized frequencies presented in the present investigation. We can relate the findings here to those from previous contrastive studies, however. On the one hand, we might have expected a cross-linguistic difference between the two sets of L1 writers as regards the frequency of marked themes, as Hasselgård $(1998,2004,2005)$ found that Norwegian fiction accommodates more non-subjects in initial position than does English. As we have seen, this does not hold true for the present material, which appears more similar to argumentative texts in that there is no such contrastive difference (Rørvik, 2013). Moreover, Shaw (2004) found a difference between English and 
Danish economics articles, in that the Danish texts had more initial circumstance adverbials than the English texts, and he found that Danish L2 writers of English behaved similarly to the L1 writers of Danish in this regard. The writers in the present L2Eng corpus underuse marked themes where Shaw's L2 writers overused them, though it should be remembered that marked themes may encompass more than just initial adverbials, so the results are not $100 \%$ comparable.

\subsection{The functions of marked themes}

We now turn to the functions of marked themes. We have calculated the frequencies of themes functioning as Adjuncts per 100 marked themes, and these are presented in Table 2.

Table 3. The frequency of marked themes functioning as Adjunct per 100 marked themes in each text and the average frequency per corpus.

\begin{tabular}{|c|c|c|c|}
\hline & L1Eng & L1Nor & L2Eng \\
\hline Text 1 & 98.3 & 95.4 & 98.4 \\
\hline Text 2 & 95.0 & 98.5 & 97.7 \\
\hline Text 3 & 100.0 & 93.4 & 100.0 \\
\hline Text 4 & 100.0 & 95.9 & 100.0 \\
\hline Text 5 & 96.3 & 86.6 & 94.1 \\
\hline Text 6 & 98.0 & 96.4 & 93.9 \\
\hline Text 8 & 99.0 & 93.3 & 100.0 \\
\hline Text 9 & 98.9 & 96.0 & 97.7 \\
\hline Text 10 & 96.7 & 94.8 & 97.1 \\
\hline Text 11 & 95.7 & 97.4 & 98.1 \\
\hline
\end{tabular}

It is suggested by the average frequencies in Table 3 that there is a cross-linguistic difference in the use of marked themes that function as Adjuncts. The L1 Norwegian texts have a lower frequency than the two English subcorpora, although Adjuncts are slightly less frequent in the L2 English corpus than in the L1 English corpus. The statistical calculations confirm the impression created by the average frequencies, in that there is a significant difference between L1Eng and L1Nor ( $\mathrm{p}=0.0058306)$ and between L2Eng and L1Nor ( $\mathrm{p}=0.0265318)$. In both cases, the effect size is very large $(\mathrm{d} \approx 1.44, \mathrm{CI}(95 \%) \approx[0.38,2.5]$ and $\mathrm{d} \approx-1.44$, $\mathrm{CI}(95 \%) \approx[-2.5,-0.38]$, respectively). Given these significant differences, we will include Figure 2 showing the distribution of marked themes functioning as Adjuncts.

Figure 2 below clearly shows that the majority of Norwegian texts have a frequency of marked themes functioning as Adjuncts that is below the frequencies in the majority of both the L1 and the L2 English texts. The shape of the plots themselves indicate that there is less variation among the L2 writers than among the two sets of L1 writers (but note the two outliers in the L2Eng corpus). With regard to the use of marked themes functioning as Adjuncts, then, we may conclude that the L2 writers have been able to conform to the pattern of usage employed by L1 writers of English, despite the potential for a transfer-related effect. 


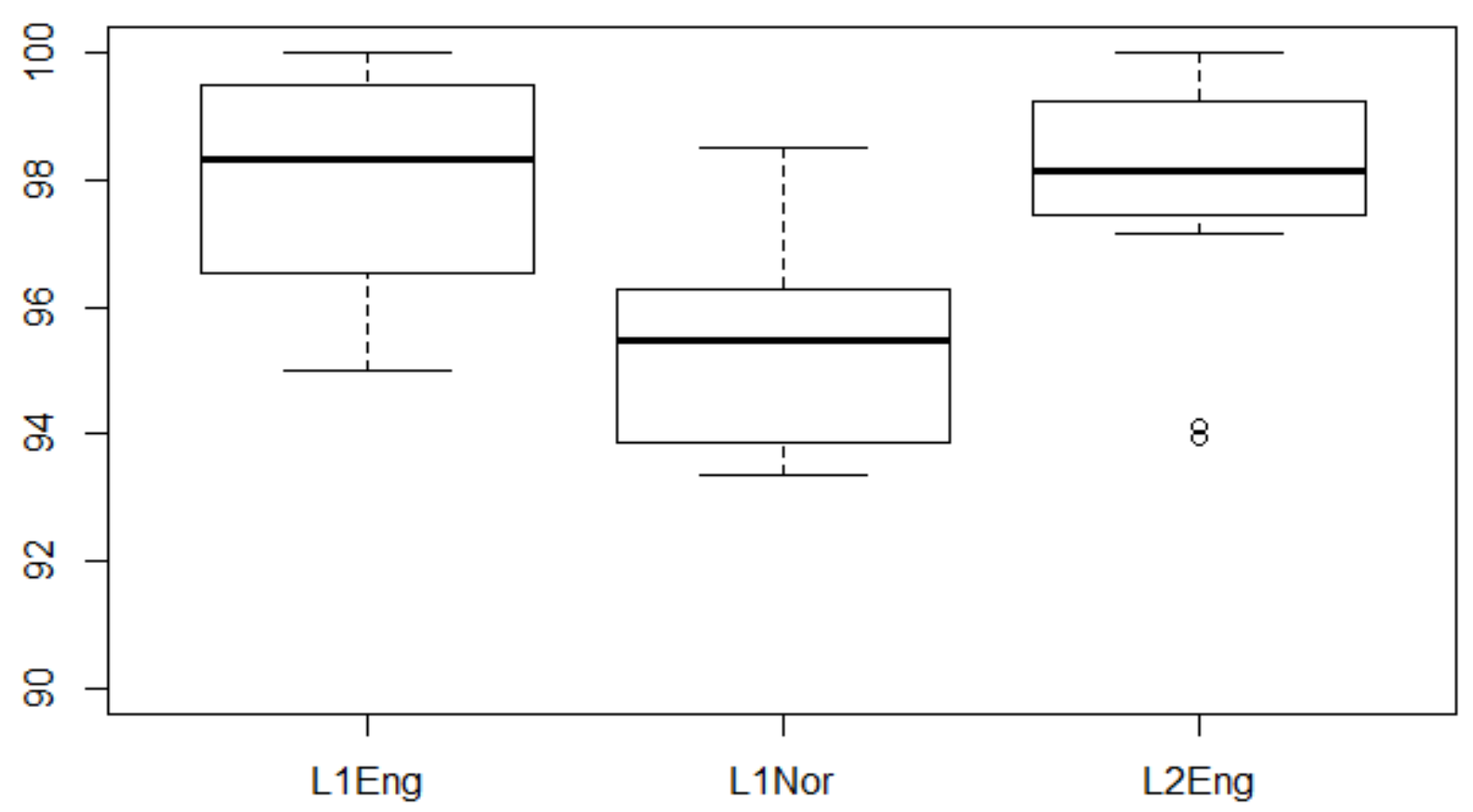

Figure 2. Distribution of marked themes functioning as Adjunct per 100 marked themes in each subcorpus.

The results for marked themes functioning as Adjuncts are more comparable to those presented in Shaw (2004), since initial circumstance adverbials will always be classified as marked themes using the present analytical framework. But here it is clear that Norwegian L2 writers of English have adapted better to English discourse conventions than the Danish L2 writers investigated by Shaw, and indeed the present L2 writers have managed to comply with English discourse conventions despite the cross-linguistic difference resulting from the lower frequency of marked themes functioning as Adjuncts in L1Nor. Hasselgård (2014) found more initial adjuncts in Norwegian than in English, in both news and fiction, which indicates that the text-type or genre also affects the use of marked themes functioning as Adjunct.

Since there were no marked themes realized by processes in the current material, the only other possible function of marked themes is that of Complement, for which the frequencies are presented in Table 4.

Table 4: The frequency of marked themes functioning as Complement per 100 marked themes in each text and the average frequency per corpus.

\begin{tabular}{|c|c|c|c|}
\hline & L1Eng & L1Nor & L2Eng \\
\hline Text 1 & 1.6 & 4.5 & 1.5 \\
\hline Text 2 & 5.0 & 1.4 & 2.2 \\
\hline Text 3 & 0.0 & 6.5 & 1.7 \\
\hline Text 4 & 0.0 & 4.0 & 0.0 \\
\hline Text 5 & 3.6 & 13.3 & 0.0 \\
\hline Text 6 & 1.9 & 3.5 & 5.8 \\
\hline Text 7 & 0.9 & 6.6 & 6.0 \\
\hline Text 8 & 1.0 & 3.9 & 0.0 \\
\hline Text 9 & 2.1 & 5.1 & 2.2 \\
\hline Text 10 & 4.2 & 2.5 & 2.8 \\
\hline Text 11 & 0.0 & 5.7 & 1.8 \\
\hline Average frequency & 1.8 & 5.2 & 2.2 \\
\hline
\end{tabular}


The average frequencies presented in Table 4 are difficult to interpret, since the two English subcorpora have several texts with no marked themes functioning as complements in them. This naturally means that the average frequencies give a distorted picture of the distribution in the corpora. The statistics show, however, that the average frequencies may be trusted in this case in that they indicate that marked themes functioning as Complements are more frequent in Norwegian than in English: we once again find a significant contrastive difference with very large effect size between L1Nor and L1Eng ( $\mathrm{p}=0.0038413, \mathrm{~d} \approx-1.52, \mathrm{CI}(95 \%) \approx[-$ $2.6,-0.45])$ and between L1Nor and L2Eng $(\mathrm{p}=0.0242967, \mathrm{~d} \approx 1.3, \mathrm{CI}(95 \%) \approx[0.26,2.33])$. The low frequencies naturally result in plots that occur towards the bottom of Figure 3:



Figure 3. Distribution of marked themes functioning as Complement per 100 marked themes in each subcorpus

There is more corpus-internal variation in the two L1 subcorpora than in the L2 corpus, but L1Nor has one outlier with a lot more marked themes functioning as Complement than the other Norwegian texts. L2Eng has two outliers with slightly higher frequencies, but these are not enough to pull the average frequency up to a figure more closely resembling that found in L1Nor. Thus, the cross-linguistic difference for marked themes functioning as Complements goes in the opposite direction to that found for Adjuncts: Complements are more frequent in Norwegian than in English, which is in line with the results presented by Hasselgård (1998, 2004). It also seems clear that, as regards both functions of marked themes found in the present material, the L2 writers have not been influenced by transfer from Norwegian, and have managed to avoid a foreign flavor in their English texts. 


\subsection{The realizations of marked themes}

In this section the focus is on the realization of marked themes, starting with marked themes realized by dependent clauses, for which the frequencies per 100 marked themes are presented in Table 5.

Table 5. The frequency of marked themes realized by dependent clauses per 100 marked themes in each text and the average frequency per corpus.

\begin{tabular}{|c|c|c|c|}
\hline & L1Eng & 27. L1Nor 3 & L2Eng \\
\hline Text 1 & 31.7 & 16.4 & 35.5 \\
\hline Text 2 & 46.3 & 23.7 & 30.0 \\
\hline Text 3 & 40.4 & 12.1 & 50.0 \\
\hline Text 4 & 28.2 & 46.7 & 57.4 \\
\hline Text 5 & 45.0 & 30.6 & 49.0 \\
\hline Text 6 & 42.6 & 26.7 & 21.2 \\
\hline Text 7 & 45.5 & 39.2 & 35.6 \\
\hline Text 8 & 59.4 & 29.3 & 31.1 \\
\hline Text 9 & 48.4 & 15.4 & 17.1 \\
\hline Text 10 & 45.1 & 21.4 & 51.9 \\
\hline Average frequency & 40.0 & 26.3 & 38.4 \\
\hline
\end{tabular}

Based on the average frequencies presented in Table 5 it seems that the L1 English texts contain more marked themes realized by dependent clauses than do the L2 English texts, and that transfer from Norwegian may play a role in lowering the frequency in L2Eng, since the Norwegian texts contain by far the lowest frequency. However, the difference between the two English corpora is not significant $(\mathrm{p}=0.5849766)$, so the only real difference is between the Norwegian subcorpus and the two corpora containing texts written in English. The difference between the Norwegian subcorpus and L2Eng is large $(\mathrm{p}=0.0341214, \mathrm{~d} \approx-1.02$, $\mathrm{CI}(95 \%) \approx[-2.02,-0.02])$, and the difference between L1Nor and the L1 English texts is very large $(\mathrm{p}=0.0028936, \mathrm{~d} \approx 1.78, \mathrm{CI}(95 \%) \approx[0.66,2.9])$. It is still possible that transfer may affect the L2 English writers, just not to the extent that it results in a significant difference between their texts and the L1 English texts. The plots in Figure 4 show a very different distribution among the L2 writers than among the writers in L1Eng.

There is much more variation in L2Eng than in L1Eng, and quite a lot of overlap between the plots for the Norwegian subcorpus and the non-native English subcorpus. It is therefore possible that a larger sample would have resulted in greater similarity between the L2 English texts and the Norwegian texts. 


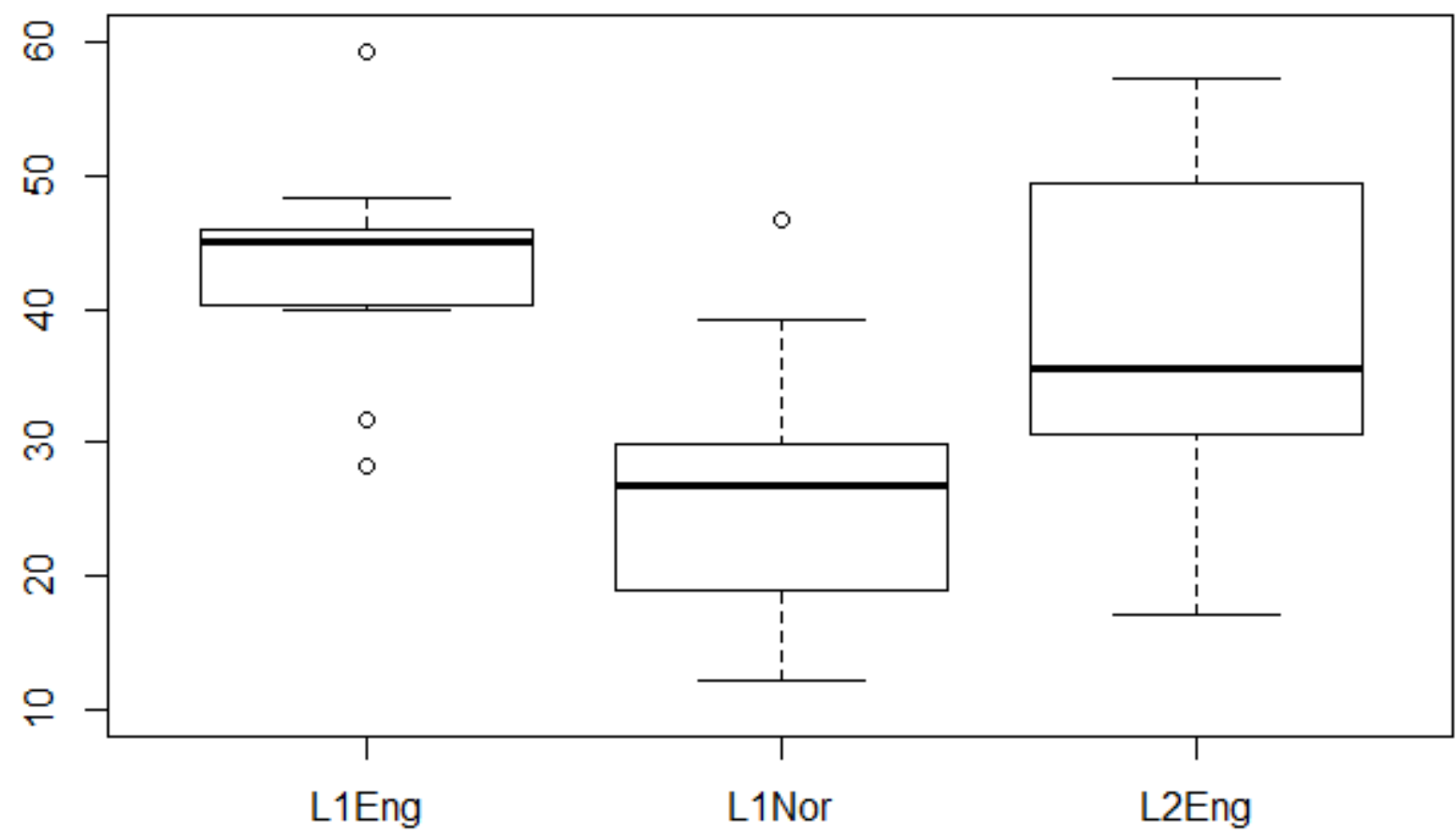

Figure 4. Distribution of marked themes realized by dependent clauses per 100 marked themes in each subcorpus

One potential explanation for the lower frequency of marked themes realized by dependent clauses in L1Nor is that the writers of English may have used a great deal of non-finite -ing clauses, which do not have an direct counterpart in Norwegian. Future studies of the kind reported on here would do well to include this variable, but for present purposes we refer to Hasselgård (2014), who did not find more initial adjuncts realized by non-finite clauses in English than Norwegian.

The second structure to be included here is prepositional phrases functioning as marked themes. Table 6 contains the normalized frequencies for these.

Table 6. The frequency of marked themes realized by prepositional phrases per 100 marked themes in each text and the average frequency per corpus.

\begin{tabular}{|c|c|c|c|}
\hline & L1Eng & L1Nor & L2Eng \\
\hline Text 1 & 55.0 & 50.0 & 60.0 \\
\hline Text 2 & 38.7 & 67.1 & 64.1 \\
\hline Text 3 & 53.1 & 53.9 & 50.0 \\
\hline Text 4 & 59.1 & 68.6 & 39.3 \\
\hline Text 5 & 48.6 & 36.6 & 41.1 \\
\hline Text 6 & 52.4 & 55.2 & 72.7 \\
\hline Text 7 & 52.4 & 66.6 & 57.6 \\
\hline Text 9 & 36.4 & 43.1 & 62.2 \\
\hline Text 10 & 39.5 & 55.1 & 65.7 \\
\hline Text 11 & 47.8 & 71.7 & 44.4 \\
\hline Average frequency & 58.8 & 61.4 & 55.3 \\
\hline
\end{tabular}

The differences between the average frequencies in Table 6 are relatively small, both between the two English subcorpora and cross-linguistically, and the differences that do occur are in 
fact non-significant for all comparisons (L1Eng vs. L2Eng: $p=0.3522646$; L1Eng vs. L1Nor: $\mathrm{p}=0.1749415$; L2Eng vs. L1Nor: $\mathrm{p}=0.9015830$ ). Hasselgård (2014: 85) reports twice as many initial prepositional phrases in Norwegian as in English, but since the present material does not exhibit the same contrastive difference, we conclude that text-type differences may influence the use of prepositional phrases in the sense that a the cross-linguistic difference found for news and fiction does not appear to exist in the case of academic articles in the field of didactics.

The final results reported on in this subsection are those concerning the marked themes realized by adverb phrases. The normalized frequencies are given in Table 7.

Table 7. The frequency of marked themes realized by adverb phrases per 100 marked themes in each text and the average frequency per corpus.

\begin{tabular}{|c|c|c|c|}
\hline & L1Eng & L1Nor & L2Eng \\
\hline Text 1 & 11.7 & 18.2 & 3.0 \\
\hline Text 2 & 7.5 & 10.4 & 0.4 \\
\hline Text 3 & 4.3 & 10.5 & 0.0 \\
\hline Text 4 & 8.5 & 15.2 & 1.6 \\
\hline Text 5 & 0.9 & 6.7 & 2.0 \\
\hline Text 6 & 5.0 & 10.6 & 0.0 \\
\hline Text 7 & 2.0 & 3.3 & 5.1 \\
\hline Text 8 & 3.1 & 13.7 & 2.2 \\
\hline Text 9 & 9.9 & 10.3 & 11.4 \\
\hline Text 11 & 2.8 & 5.1 & 0.0 \\
\hline Average frequency & 1.1 & 11.4 & 2.7 \\
\hline
\end{tabular}

On the basis of the average frequencies in Table 7 it would seem that the two English corpora are fairly similar as regards marked themes realized by adverb phrases, although there is a slightly higher frequency in the L1 English texts than in the L2 texts. What is more striking, however, is the fact that the Norwegian texts contain twice as many adverb phrases functioning as marked themes than do the L1 English texts, and nearly four times as many as can be found in the L2 English material. It should come as no surprise, therefore, that the only significant differences here are the cross-linguistic ones. The difference between L1Nor and L1Eng is very large $(\mathrm{p}=0.0243690, \mathrm{~d} \approx-1.3, \mathrm{CI}(95 \%) \approx[-2.3,-0.2])$, and the difference between L1Nor and L2Eng is huge $(\mathrm{p}=0.0243690, \mathrm{~d} \approx 2.1, \mathrm{CI}(95 \%) \approx[0.92,3.2])$. As there are significant differences between the subcorpora with regard to this feature, we include the boxplots in Figure 5. 


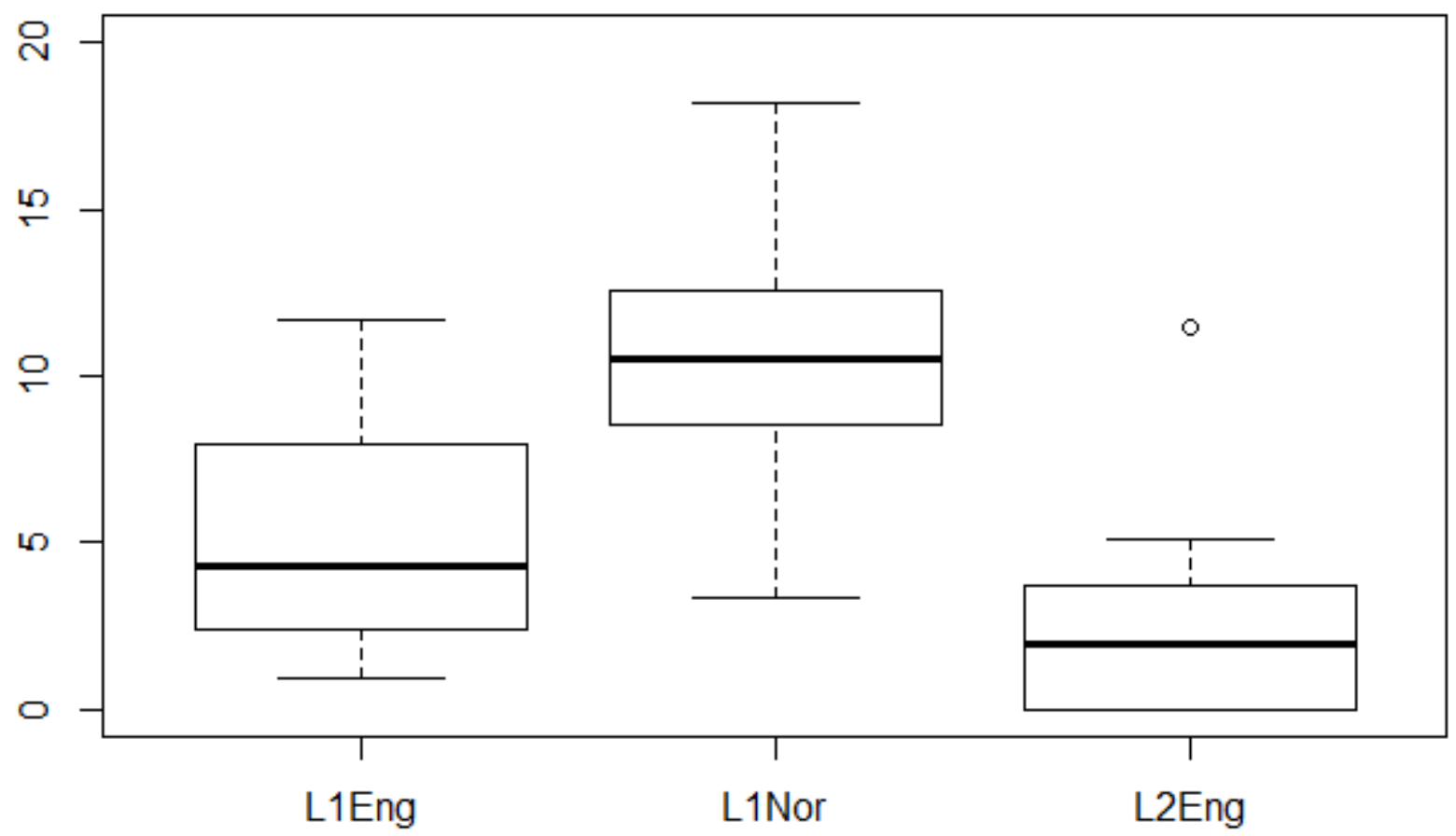

Figure 5. Distribution of marked themes realized by adverb phrases per 100 marked themes in each subcorpus.

The boxplots in Figure 5 show that there is more variation within the L1Nor subcorpus than within the two other corpora, and this might imply a need to be cautious regarding the firmness of conclusions drawn about the existence of cross-linguistic differences in the use of adverb phrases: there is quite a lot of overlap between the lower range of the Norwegian texts and the L1 English texts, for instance. However, it is also clear that the upper range of the Norwegian frequencies is well above all of the L1Eng values, so on the basis of the present material, at least, there is a clear contrastive difference. Despite this, the L2 writers have managed to follow English conventions in their adverb-phrase usage of the kind discussed here. The contrastive difference matches that found in Hasselgård (2014), but it should be mentioned that the frequencies there are very low overall.

\subsection{The meanings expressed by marked themes}

As described in Section 3.4, we include findings regarding seven meanings expressed by marked themes in our discussion here. The meanings where significant differences were identified between the subcorpora will be discussed first. These include 'place', 'instrument', 'concession', and 'purpose'. Next, we will present a brief overview of those meanings where no significant differences were found between the subcorpora, i.e. 'time', 'condition', and 'reason'. We end this subsection with a comparison of the present findings and the results from previous studies regarding the meaning expressed by marked themes.

\subsubsection{Meanings where there is a significant difference}

The first meaning where there is a significant difference between two or more of the subcorpora is 'place'. Table 8 presents the normalized frequencies for this meaning. 
Table 8. The frequency of marked themes expressing 'place' per 100 marked themes in each text and the average frequency per corpus.

\begin{tabular}{|c|c|c|c|}
\hline & L1Eng & L1Nor & L2Eng \\
\hline Text 1 & 38.3 & 38.6 & 35.2 \\
\hline Text 2 & 6.3 & 35.8 & 21.1 \\
\hline Text 3 & 14.9 & 34.2 & 7.7 \\
\hline Text 4 & 5.6 & 32.3 & 9.8 \\
\hline Text 5 & 14.4 & 10.0 & 15.7 \\
\hline Text 6 & 15.8 & 29.4 & 39.4 \\
\hline Text 7 & 25.7 & 43.3 & 30.5 \\
\hline Text 9 & 9.4 & 25.5 & 15.6 \\
\hline Text 10 & 8.8 & 22.4 & 25.7 \\
\hline Text 11 & 7.0 & 33.3 & 22.2 \\
\hline Average frequency & 35.6 & 38.6 & 21.5 \\
\hline
\end{tabular}

The only significant difference among the three subcorpora as regards the frequency of adverbials expressing 'place' is between the two L1 corpora, where the effect size is very large $(\mathrm{p}=0.0050644, \mathrm{~d} \approx-1.4, \mathrm{CI}(95 \%) \approx[-2.4,-0.3])$. Figure 6 illustrates the difference, and additionally shows a much greater degree of corpus-internal variation in L1Eng than in L1Nor, with the L2 writers of English in between the other two groups.

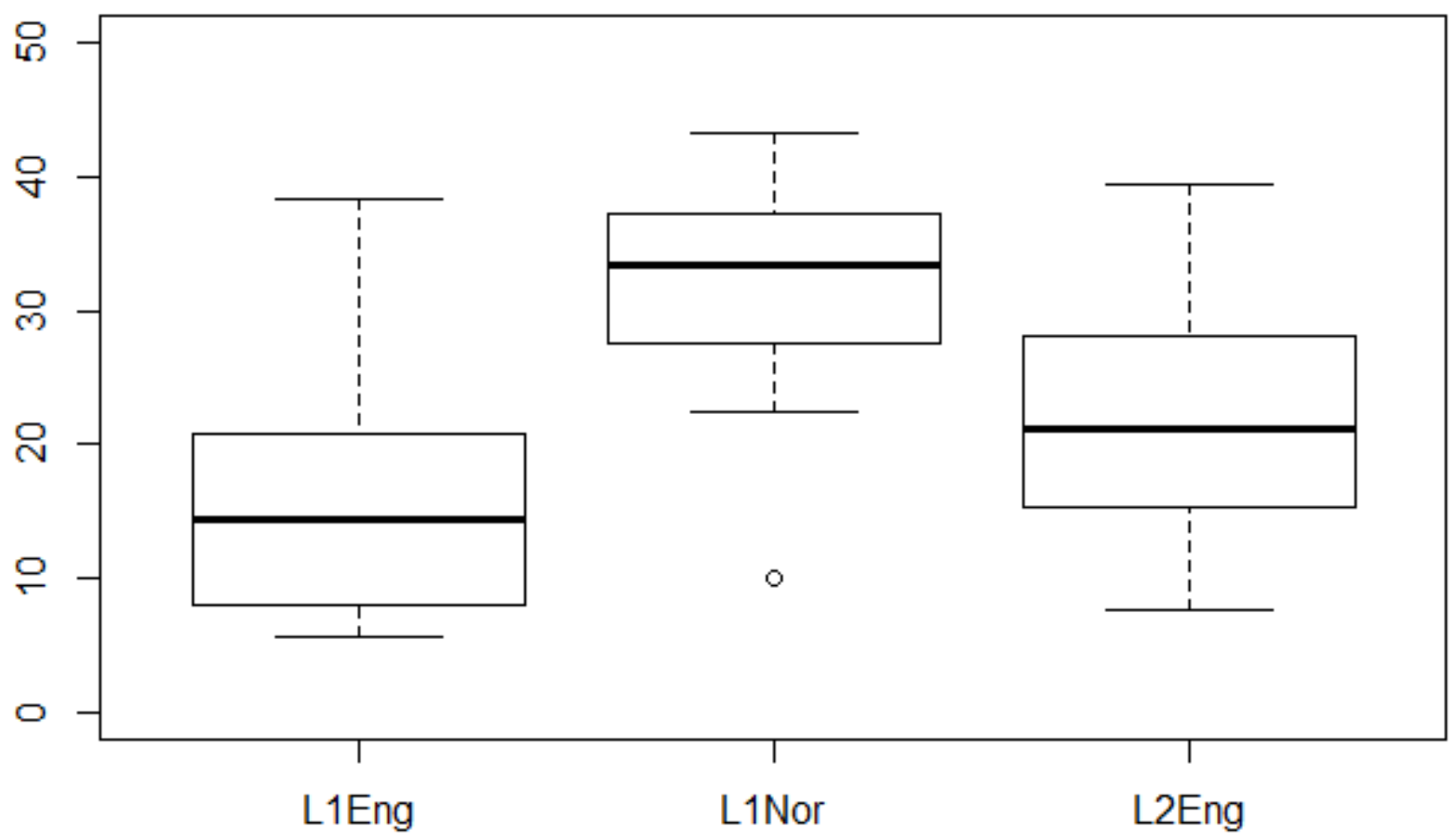

Figure 6. Distribution of marked themes expressing 'place' per 100 marked themes in each subcorpus.

Next we will examine the frequencies for marked themes expressing 'instrument', which are given in Table 9. 
Table 9. The frequency of marked themes expressing 'instrument' per 100 marked themes in each text and the average frequency per corpus.

\begin{tabular}{|c|c|c|c|}
\hline & L1Eng & L1Nor & L2Eng \\
\hline Text 1 & 1.7 & 2.3 & 3.0 \\
\hline Text 2 & 3.8 & 1.5 & 11.1 \\
\hline Text 3 & 8.5 & 1.3 & 0.5 \\
\hline Text 4 & 5.6 & 0.0 & 0.0 \\
\hline Text 5 & 2.7 & 10.0 & 3.9 \\
\hline Text 6 & 8.9 & 1.2 & 6.1 \\
\hline Text 7 & 5.0 & 0.0 & 3.4 \\
\hline Text 8 & 5.2 & 0.0 & 13.3 \\
\hline Text 9 & 1.1 & 0.0 & 2.9 \\
\hline Text 10 & 5.6 & 2.6 & 0.0 \\
\hline Avert 11 & 5.6 & 2.9 & 4.9 \\
\hline
\end{tabular}

Although the two English subcorpora have exactly the same average frequency, it is only the difference between L1Eng and L1Nor that is significant, with a very large effect size $(\mathrm{p}=0.0286952, \mathrm{~d} \approx 1.3, \mathrm{CI}(95 \%) \approx[0.28,2.3])$. The reason for this is probably easier to understand if we look at the distribution within each subcorpus, since, as illustrated in Figure 7, the texts in L1Eng are much more consistently placed around the average of 4.9, whereas L2Eng has several texts with no marked themes expressing 'instrument' and several texts that score higher than in any of the two other subcorpora. The Norwegian texts, on the contrary, include one outlier with a relatively high frequency of 'instrument' meanings, and also four texts with no such marked themes, and in general extremely low frequencies.

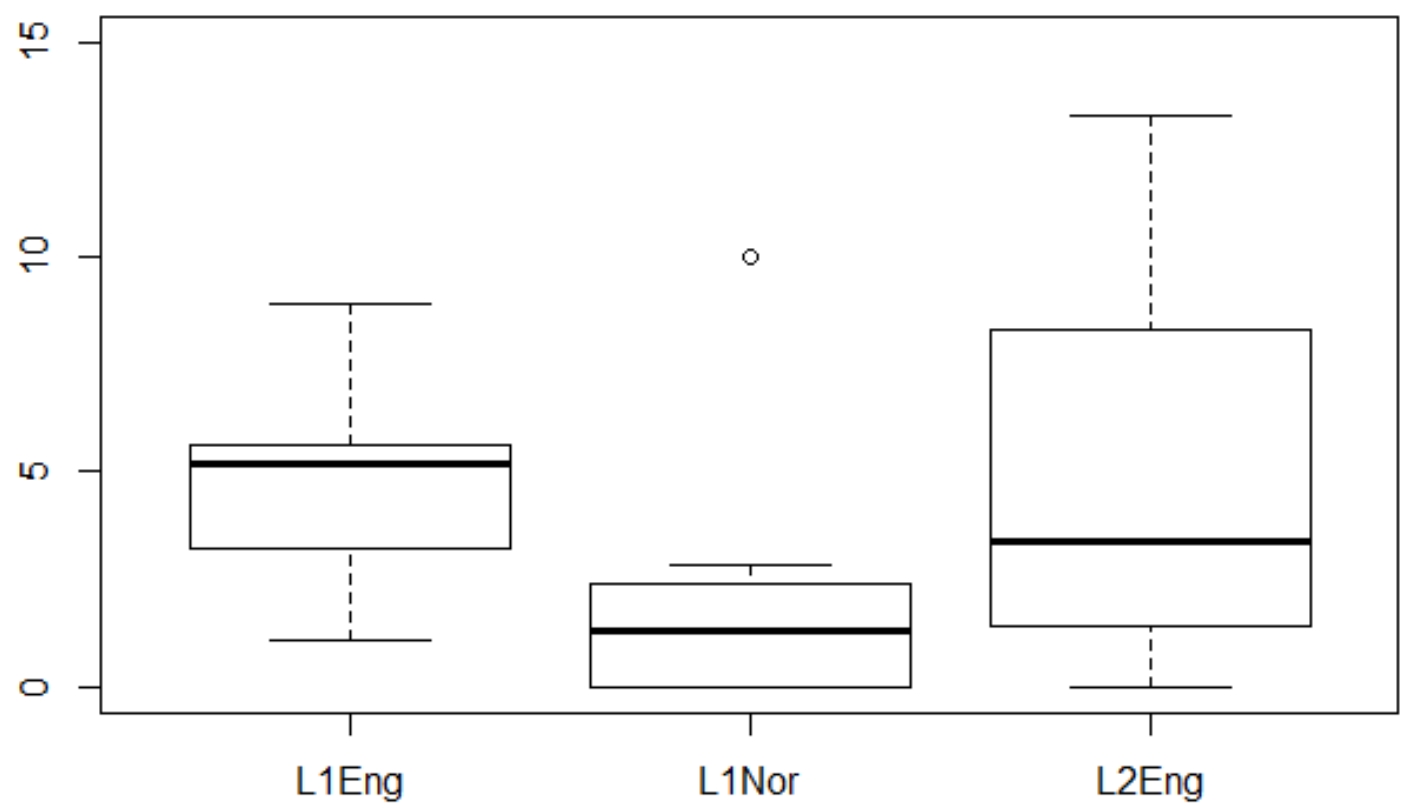

Figure 7. Distribution of marked themes expressing 'instrument' per 100 marked themes in each subcorpus.

Marked themes expressing 'concession' are slightly more frequent than those expressing 'instrument', as shown by the figures in Table 10. 
Table 10. The frequency of marked themes expressing 'concession' per 100 marked themes in each text and the average frequency per corpus.

\begin{tabular}{|c|c|c|c|}
\hline & L1Eng & L1Nor & L2Eng \\
\hline Text 1 & 6.7 & 9.1 & 12.1 \\
\hline Text 2 & 12.5 & 7.5 & 3.4 \\
\hline Text 3 & 12.8 & 1.3 & 30.8 \\
\hline Text 4 & 7.0 & 2.0 & 18.0 \\
\hline Text 5 & 18.0 & 3.3 & 5.9 \\
\hline Text 6 & 9.9 & 7.1 & 9.1 \\
\hline Text 7 & 11.9 & 0.0 & 15.3 \\
\hline Text 8 & 27.1 & 15.7 & 13.3 \\
\hline Text 10 & 16.5 & 5.2 & 11.4 \\
\hline Text 11 & 15.5 & 10.3 & 24.1 \\
\hline Average frequency & 17.8 & 5.7 & 13.4 \\
\hline
\end{tabular}

The two English subcorpora are practically identical in terms of how many times the writers use marked themes expressing 'concession'. This does not necessarily mean that the corpusinternal distribution is identical, as was discussed above with regard to 'instrument', and indeed Figure 8 shows that there are distribution differences for 'concession' as well.

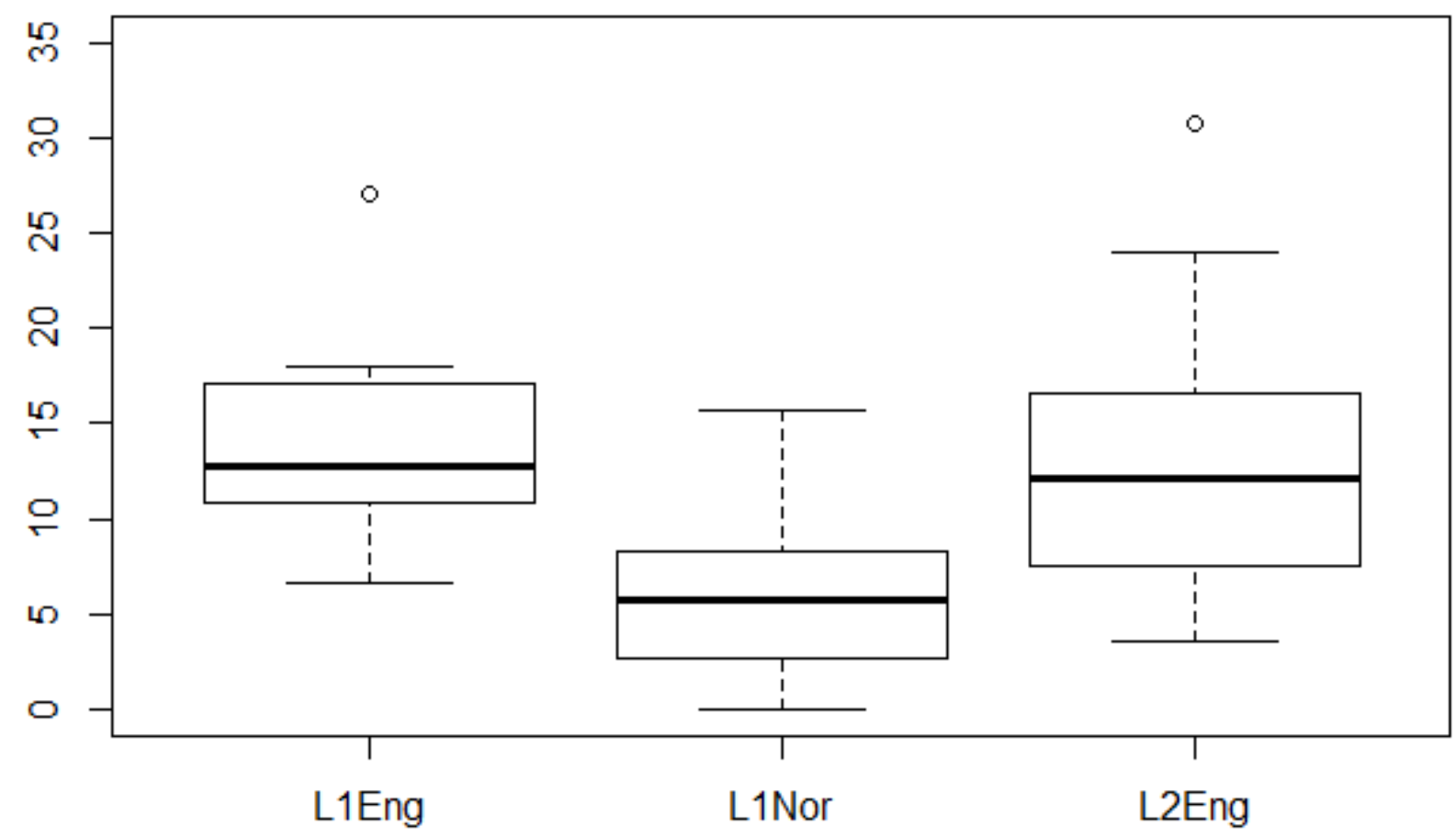

Figure 8. Distribution of marked themes expressing 'concession' per 100 marked themes in each subcorpus.

There is more variation within the L2 English corpus than within the L1 English corpus, but a sufficient number of the texts are centered around the mean for there not to be a significant difference between these two subcorpora. However, each of them in turn are significantly different from the L1 Norwegian corpus, despite some overlap in the boxplots (L1Eng vs. L1Nor: $\mathrm{p}=0.0170723, \mathrm{~d} \approx 1.5, \mathrm{CI}(95 \%) \approx[0.46,2.6]$; L2Eng vs. L1Nor: $\mathrm{p}=0.0310533, \mathrm{~d} \approx-1$, $\mathrm{CI}(95 \%) \approx[-2.09,-0.08])$. 
Finally, we will look at the frequencies of marked themes expressing 'purpose', which can be found in Table 11.

Table 11. The frequency of marked themes expressing 'purpose' per 100 marked themes in each text and the average frequency per corpus.

\begin{tabular}{|c|c|c|c|}
\hline & L1Eng & L1Nor & L2Eng \\
\hline Text 1 & 5.0 & 0.0 & 0.0 \\
\hline Text 2 & 15.0 & 1.5 & 1.1 \\
\hline Text 3 & 4.3 & 3.9 & 11.5 \\
\hline Text 4 & 1.4 & 0.0 & 3.3 \\
\hline Text 5 & 2.7 & 0.0 & 3.9 \\
\hline Text 6 & 1.0 & 3.5 & 0.0 \\
\hline Text 7 & 4.0 & 0.0 & 8.5 \\
\hline Text 8 & 7.3 & 0.0 & 6.7 \\
\hline Text 9 & 5.5 & 1.7 & 0.0 \\
\hline Text 10 & 5.6 & 5.1 & 1.9 \\
\hline Avext 11 & 7.8 & 1.4 & 4.9 \\
\hline
\end{tabular}

The difference between L1Eng and L2Eng is not significant $(\mathrm{p}=0.6515050)$, but the difference between L1Eng and the Norwegian texts is $(\mathrm{p}=0.0292506, \mathrm{~d} \approx 1.3, \mathrm{CI}(95 \%) \approx$ $[0.31,2.4])$, so once again we have identified a feature where the L2 writers have managed to comply with English discourse conventions despite a contrastive difference. The difference between the L2 texts and the Norwegian texts is not significant, so it is possible that there is a slight transfer effect, but if so the L2 writers have come sufficiently far in their development to approach native-speaker usage with regard to marked themes expressing 'purpose'. As is illustrated in Figure 9, however, there is a great deal of variation in the L2 subcorpus, and some texts may be approaching overuse of 'purpose'.

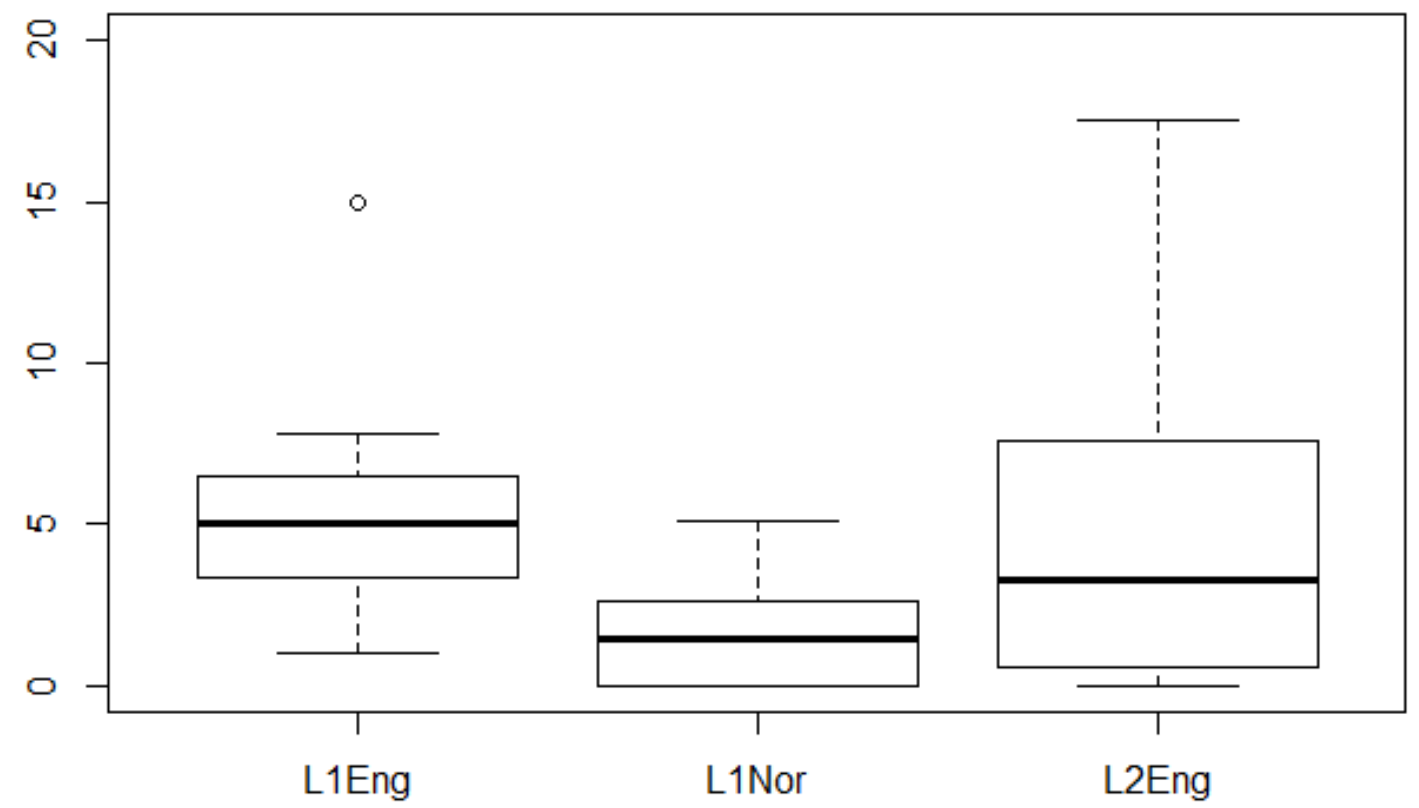

Figure 9. Distribution of marked themes expressing 'purpose' per 100 marked themes in each subcorpus.

Although there is some overlap between the plots for the two native-language corpora, there are generally lower frequencies in the Norwegian subcorpus, and also five texts where there are no marked themes expressing purpose. 


\subsubsection{Meanings where there is no significant difference}

No significant differences were found for the three remaining meanings discussed here, namely 'time', 'condition', and 'reason'. We nonetheless include the frequencies for these meanings in the three subcorpora, since it is interesting to compare the present findings with relevant findings from previous studies. The frequencies for all three meanings are given in Table 12.

Table 12. The frequency of marked themes expressing 'time', 'condition', and 'reason' per 100 marked themes in each text and the average frequency per corpus.

\begin{tabular}{|c|c|c|c|c|c|c|c|c|c|}
\hline & \multicolumn{4}{|c|}{ 'Time' } & \multicolumn{1}{c|}{ 'Condition' } & \multicolumn{4}{c|}{ 'Reason' } \\
\hline & LlEng & L1Nor & L2Eng & L1Eng & L1Nor & L2Eng & L1Eng & L1Nor & L2Eng \\
\hline Text 1 & 16.7 & 9.1 & 28.8 & 3.3 & 4.5 & 4.5 & 6.7 & 11.4 & 6.1 \\
\hline Text 2 & 15.0 & 20.9 & 20.0 & 1.3 & 6.0 & 1.1 & 11.3 & 0.0 & 6.7 \\
\hline Text 3 & 23.4 & 19.7 & 12.3 & 0.0 & 13.2 & 7.0 & 10.6 & 1.3 & 12.3 \\
\hline Text 4 & 31.0 & 39.4 & 7.7 & 5.6 & 2.0 & 0.0 & 9.9 & 0.0 & 23.1 \\
\hline Text 5 & 23.4 & 13.3 & 16.4 & 3.6 & 20.0 & 6.6 & 5.4 & 6.7 & 6.6 \\
\hline Text 6 & 30.7 & 7.1 & 9.8 & 2.0 & 11.8 & 5.9 & 8.9 & 5.9 & 15.7 \\
\hline Text 7 & 16.8 & 23.3 & 9.1 & 5.0 & 0.0 & 0.0 & 9.9 & 10.0 & 6.1 \\
\hline Text 8 & 6.3 & 13.7 & 22.0 & 5.2 & 11.8 & 3.4 & 8.3 & 3.9 & 5.1 \\
\hline Text 9 & 30.8 & 22.4 & 22.2 & 3.3 & 8.6 & 2.2 & 7.7 & 13.8 & 8.9 \\
\hline Text 10 & 23.9 & 17.9 & 25.7 & 0.0 & 0.0 & 0.0 & 9.9 & 7.7 & 2.9 \\
\hline Text 11 & 17.8 & 20.0 & 7.4 & 2.2 & 4.3 & 3.7 & 2.2 & 4.3 & 14.8 \\
\hline Average frequency & 21.4 & 18.8 & 16.5 & 2.9 & 7.5 & 3.1 & 8.2 & 5.9 & 9.8 \\
\hline
\end{tabular}

As Table 12 shows, 'time' is the most frequent of the three meanings, followed by 'reason' and 'condition'. If we look more closely at the frequencies for 'time', we can see that there are slight differences between the corpora: the highest frequency is found in L1Eng, the second highest in L1Nor, and the lowest in L2Eng. 'Condition' is more frequent in Norwegian than in English, and marked themes expressing 'reason' are most frequent in the two English subcorpora. However, these slight differences in the normalized frequencies were not sufficiently large to be significant.

\subsubsection{Meanings expressed by marked themes: comparison with previous research}

As discussed in Section 5.4.1, the meanings 'instrument', 'concession', and 'purpose' were more frequent in the L1 English texts than in the Norwegian texts, with 'concession' also being more frequent in L2 English. 'Place' was found to be more frequent in Norwegian than in English. In Section 5.4.2 it was reported that no significant contrastive difference was found for the meanings 'time', 'condition', and 'reason'. As discussed above it is difficult to relate these findings to the percentages reported in related previous studies, but we can add to the discussion the frequency ranking of the meanings discussed here. Thus, the most frequent meanings in L1Eng are 'time', 'place', and 'concession', in L2Eng they are 'place', 'time', and 'concession', and in L1Nor the most frequent is 'place' followed by 'time' and 'condition'. Table 13 summarizes the findings from previous studies by ranking the three most frequent meanings identified in each study. ${ }^{5}$

\footnotetext{
${ }^{5}$ Note that not all of these studies investigate marked themes specifically, and that some of them employ more inclusive definitions of marked themes than the framework used in the present study. The reader is referred to the individual studies for details.
} 
Table 13. The three most frequent meanings expressed by marked themes in previous studies.

\begin{tabular}{|c|c|c|c|c|}
\hline Study & Material & Meaning 1 & Meaning 2 & Meaning 3 \\
\hline Gosden 1992 & Physics, chemistry, and biology & 'place' & $\begin{array}{l}\text { 'contrastive/ } \\
\text { concessive' }\end{array}$ & 'time' \\
\hline Martínez 2003 & $\begin{array}{l}\text { Method and discussion sections } \\
\text { in biology }\end{array}$ & 'purpose' & 'time' & 'place' \\
\hline $\begin{array}{l}\text { Heng \& } \\
\text { Ebrahimi } 2012\end{array}$ & $\begin{array}{l}\text { Abstracts in applied linguistics } \\
\text { and economics }\end{array}$ & 'contrast' & 'time' & 'condition' \\
\hline $\begin{array}{l}\text { Hasselgård } \\
2014\end{array}$ & $\begin{array}{l}\text { English and Norwegian fiction } \\
\text { and news }\end{array}$ & $\begin{array}{l}\text { E \& N news \& } \\
\text { fiction: 'time' }\end{array}$ & $\begin{array}{l}\text { E \& N news: } \\
\text { 'contingency' } \\
\text { E \& N fiction: } \\
\text { 'space' }\end{array}$ & $\begin{array}{l}\text { E \& N news: } \\
\text { 'space' } \\
\text { E \& N fiction: } \\
\text { 'contingency' }\end{array}$ \\
\hline Ebrahimi 2016 & $\begin{array}{l}\text { Method sections in applied } \\
\text { linguistics (AL), psychology } \\
\text { (P), and chemistry (C) }\end{array}$ & $\begin{array}{l}\text { AL: 'purpose', } \\
\text { 'condition' } \\
\text { P: 'purpose' } \\
\text { C: 'time' }\end{array}$ & $\begin{array}{l}\text { AL/P: 'location' } \\
\text { C: 'purpose' }\end{array}$ & $\begin{array}{l}\text { AL: 'contrast' } \\
\text { P: 'time' } \\
\text { C: 'condition', } \\
\text { 'location' }\end{array}$ \\
\hline Present study & $\begin{array}{l}\text { L1 Norwegian, L1 English, and } \\
\text { L2 English articles in didactics }\end{array}$ & $\begin{array}{l}\text { L1Nor: 'place' } \\
\text { L1Eng: 'time' } \\
\text { L2Eng: 'place' }\end{array}$ & $\begin{array}{l}\text { L1Nor: 'time' } \\
\text { L1Eng: 'place' } \\
\text { L2Eng: 'time' }\end{array}$ & $\begin{array}{l}\text { L1Nor: } \\
\text { 'condition' } \\
\text { L1Eng: } \\
\text { 'concession' } \\
\text { L2Eng: } \\
\text { 'concession' }\end{array}$ \\
\hline
\end{tabular}

The three most frequent meanings in each of the present subcorpora all appear among the meanings listed in Table 13, but it seems clear that L1, text type and/or academic discipline influences the internal ranking of meanings expressed by marked themes. Larger datasets are required in order to determine whether articles within didactics vary significantly from other disciplines in this regard, but it does seem to be the case that academic disciplines across the board have in common a fixed set of meanings expressed by marked themes, which may serve as text-structuring strategies by means of which the reader can be guided through the text.

\section{Conclusion}

Two research questions formed the starting point for this study. The first asked to what extent there were contrastive differences between L1 writers of Norwegian and English in the frequency, functions and realizations of marked themes, and in the meanings expressed by marked themes. The results showed that there was no difference in the frequency of marked themes, but fewer marked themes functioning as Adjuncts and more functioning as Complements in Norwegian than in English. In terms of the realization of marked themes there were fewer dependent clauses in Norwegian than in English, but more adverb phrases, and as regards the meanings expressed by marked themes it was found that 'place' was more frequent in Norwegian than English, but that 'instrument', 'concession', and 'purpose' were more frequent in English.

The second research question focused on the extent to which L2 writers of English had been able to adapt to English discourse conventions, and whether any evidence of transfer from Norwegian could be found. The only difference between the L1 and L2 writers that could be found was that the L2 writers underused marked themes. This difference could not be related to transfer.

Previous research has shown that text type, academic discipline, and language may influence thematic structure. The present study provides additional evidence that discipline and text type play a role, since the results differ from some previous studies (e.g. Hasselgård, 
1998 and Shaw, 2004) in not finding a higher proportion of marked themes in Norwegian (or a Scandinavian language, in the case of Shaw, 2004) than in English. We consider this the main contribution of the present paper, in addition to the empirical evidence collated about thematic structure in didactics articles which can serve as the basis for evidence-based teaching of academic writing.

\section{References}

Babaii, E., Atai, M. R. and Shoja, L. 2016. A Comparison of Thematic Choices and Thematic Progression Patterns in the Research Articles of Well-established and Emerging Disciplines. Iranian Journal of Applied Linguistics (19)2: 33-60.

Carter-Thomas, S. and Rowley-Jolivet, E. 2008. If-conditionals in medical discourse: From Theory to Disciplinary Practice. Journal of English for Academic Purposes (7): 191-205.

Davies, F. 1997. Marked Theme as a Heuristic for Analysing Text-Type, Text and Genre. In Applied Languages: Theory and Practice in ESP, J. Pique and D. J. Viera (eds), 45-79. Valencia: Universitat de Valencia.

Ebrahimi, S. F. 2016. Across Disciplinary Study of Marked Theme in Method Sections. The Journal of Teaching English for Specific and Academic Purposes (4)3: 689-699.

Ebrahimi, S. F., Chan, S. H. and Tan, B. H. 2014. Cross-Disciplinary and Cross-Linguistic Manifestations of Theme in Academic Writing. Pertanika Journal of Social Sciences \& Humanities (22)3: 695-707.

Faarlund, J. T., Lie, S. and Vannebo, K. I. 1997. Norsk Referansegrammatikk. Oslo: Universitetsforlaget.

Gilquin, G. 2000/2001. The Integrated Contrastive Model. Spicing up your data. Languages in Contrast 3(1): 95-123.

Gilquin, G. 2008. Combining Contrastive and Interlanguage Analysis to Apprehend Transfer: Detection, Explanation, Evaluation. In Linking Up Contrastive and Learner Corpus Research, G. Gilquin, S. Papp and M. B. Díez-Bedmar (eds), 3-33. Amsterdam - New York: Rodopi.

Gosden, H. 1992. Discourse Functions of Marked Theme in Scientific Research Articles. English for Specific Purposes (11): 207-224.

Granger, S. 1996. From CA to CIA and Back: An Integrated Approach to Computerized Bilingual and Learner Corpora. In Languages in Contrast. Papers from a Symposium on Text-based Crosslinguistic Studies, K. Aijmer, B. Altenberg and M. Johansson (eds), 37-52. Lund: Lund University Press.

Gray, B. 2015. On the Complexity of Academic Writing. Disciplinary Variation and Structural Complexity. In Corpus-Based Research in Applied Linguistics: Studies in Honor of Doug Biber, V. Cortes and E. Csomay (eds), 49-77. Amsterdam: John Benjamins.

Halliday, M. A. K. 2004. An Introduction to Functional Grammar. $3^{\text {rd }}$ edition, revised by C. M. I. M. Matthiessen. London: Arnold.

Hasselgård, H. 1998. Thematic Structure in Translation between English and Norwegian. In Corpora and Cross-linguistic Research: Theory, Method, and Case Studies, S. Johansson and S. Oksefjell (eds), 145-167. Amsterdam: Rodopi.

Hasselgård, H. 2004. Thematic Choice in English and Norwegian. Functions of Language 11(2): 187212.

Hasselgård, H. 2005. Theme in Norwegian. In Semiotics from the North. Nordic approaches to Systemic Functional Linguistics, K. L. Berge and E. Maagerø (eds), 35-47. Oslo: Novus Press.

Hasselgård, H. 2014. Discourse-Structuring Functions of Initial Adverbials in English and Norwegian News and Fiction. Languages in Contrast (14)1: 73-92.

Heng, C. S. and Ebrahimi, S. F. 2012. Marked Themes as Context Frames in Research Article Abstracts. GEMA Online Journal of Language Studies (12)4: 1147-1164.

Hunt, K. W. 1965. Grammatical structures written at three grade levels. NCTE Research Report No. 3. Champaign, Illinois: National Council of Teachers of English. Available at 
https://files.eric.ed.gov/fulltext/ED113735.pdf. [last accessed February 27 2018]

Hyland, K. 2000. Disciplinary discourses: Social Interaction in Academic Writing. Harlow, Essex: Pearson.

Jensen, B. U. 2017. Leksikosyntaktiske trekk og skriveverktøy. En kvantitativ unders $\emptyset$ kelse av tekster skrevet for hånd og på tastatur av elever $i$ VGl. PhD thesis, University of Bergen.

Lado, Robert. 1957 [1971]. Linguistics across Cultures: Applied Linguistics for Language Teachers. Ann Arbor MI: University of Michigan Press.

Martínez, I. A. 2003. Aspects of Theme in the Method and Discussion Sections of Biology Journal Articles in English. Journal of English for Academic Purposes (2): 103-123.

Moyano, E. I. 2016. Theme in English and Spanish. Different Means of Realization for the Same Textual Function. English Text Construction (9)1: 190-220.

North, S. 2005a. Different Values, Different Skills? A Comparison of Essay Writing by Students from Arts and Science Backgrounds. Studies in Higher Education 30(5): 517-533.

North, S. 2005b. Disciplinary Variation in the Use of Theme in Undergraduate Essays. Applied Linguistics 26(3): 431-452.

Peña, E. A. and Slate, E. H. 2014. gvlma: Global Validation of Linear Models Assumptions (R package version 1.0.0.2). Available at https://cran.rproject.org/web/packages/gvlma/gvlma.pdf. [last accessed February 27 2018]

RStudio Team. (2015). RStudio: Integrated Development for R. RStudio, Inc., Boston, MA. Available at http: / / www.rstudio.com/ [last accessed February 27 2018]

Rørvik, S. 2013. Texture in learner language. PhD thesis, University of Oslo.

Sawilowsky, S. S. 2009. New Effect Size Rules of Thumb. Journal of Modern Applied Statistical Methods (8)2: 597-599.

Shaw, P. 2004. Sentence Openings in Academic Economics Articles in English and Danish. Nordic Journal of English Studies 3(2): 67-84.

Torchiano, M. 2017. effsize: Efficient Effect Size Computation (R package version 0.7.1). Available at https://cran.r-project.org/web/packages/effsize/effsize.pdf. [last accessed February 27 2018]

Valipour, V., Nader, A. and Asl, H. D. 2017. The Generic Structures and Lexico-Grammaticality in English Academic Research Papers. Southern African Linguistics and Applied Language Studies (35)2: 169-182.

Corresponding author's address

Sylvi Rørvik

Department of Humanities, Faculty of Education

Inland Norway University of Applied Sciences

PO box 400

2418 Elverum

Norway

sylvi.rorvik@inn.no 